\title{
Neurotrophic keratopathy
}

INSERM

\section{Source}

INSERM. (1999). Orphanet: an online rare disease and orphan drug data base.

Neurotrophic keratopathy. ORPHA:137596

Neurotrophic keratopathy is a rare degenerative disease of the cornea characterized by reduction or loss of corneal sensitivity that can be asymptomatic or present with red-eye and, during the early stages of the disease, a minor decrease in visual acuity. It eventually leads to loss of vision. 